\title{
Comparison of the fin-tech evergreen fund in China and U.S.A
}

\author{
Antonia Tong
}

Lincoln University College,Malaysia

2021

\begin{abstract}
Compared to a Chinese investor, the U.S. investors invest in Fin-Tech evergreen fund is not a strange financial activity. In the fast-developing of different technology nowadays, the US. Fin-Tech evergreen investors are always attempting to catch the wave of the opportunity to invest in new financial technology companies that will almost like investing in Apple, Microsoft, SpaceX, or Teslar twenty years ago. This article intends to introduce, compare, and analyst the fin-tech evergreen development in both the USA and China. Fin-Tech Evergreen financing is a concept used to describe the gradual infusion of funds into a fin-tech company. It is feasible to organize for the receipt of venture capital money in advance. Nevertheless, with FinTech's evergreen investment, investors provide cash in incremental payments throughout the company's or product's development phase. It is a perpetual fund architecture with no set end date. It frequently provides investors with the ability to exit their commitment and allows the fund manager to acquire additional cash. Investors are allowed to reinvest cash generated by realized returns, thus the term "evergreen." With a thorough explanation of the two most powerful economic powers' investment direction of the evergreen fund, the general public will learn more about the evergreen fund's future and destiny.
\end{abstract}

Keywords: Asia, Asian, Blockchain, Capitalism, Chinese, communism, Cryptocurrency, Economic, Evergreen fund, Fin-Tech, U.S.A 


\section{Introduction and Background}

Fin-tech is a technological advancement that interacts with standard finance procedures in the provision of financial services. It is one of the growing sectors that uses technology to enhance financial activities. Over the last 10 years, the advancement of cryptocurrency has pushed the entire globe to a whole new degree of financial activities and has changed the way individuals spend, trade, lend, and save money. Fin-tech services include the use of blockchain Dapps on smart devices for mobile banking, investing, and borrowing.

Cryptocurrency is an illustration of how innovation is being used to make financial services accessible to the wider public. Financial institutions include both startups and established financial institutions and technology firms that are attempting to substitute or improve the use of services provided by various financial institutions such as credit card companies, banks, traditional credit agencies, real estate escrow companies, and so on.

The fin-tech industry refers to innovative apps, procedures, goods, or business practices in the financial services sector that is made up of one or more complementing financial services and delivered as an end-to-end process through the World wide web. Fin-tech integrates the Internet with actual financial service providers and automates all business processes. It may also be defined as "any creative ideas that enhance financial service operations by offering technological solutions based on various business conditions," with the ideas potentially leading to new business models or even new enterprises. For example, supply chain management, cloud-data service, online discount platforms shopping service, real estate purchasing, and property management, etc. Another area connected to most of the human activity such as the self-operation system in medical, industrial, and management systems.

In the USA, the most famous evergreen fund is General Atlantic ${ }^{[10]}$ (AltAssets, 2018). The Wall Street Journal reported in September 2020 that the private equity firm General Atlantic [10] led a $\$ 300$ million fundraising round for Brazilian fintech startup Neon Pagamentos SA to assist the firm's continuing expansion.

\section{Methodology}

The current round of investment comes shortly after the firm assisted the business in a $\$ 92$ million Series B fundraising round in 2019, bringing the total cash generated to more than $\$ 400$ million. In 2018, Neon raised a \$22 million Series A round.

But why the biggest $\mathrm{VC}^{[1]}$ fund favors fin-tech amid the pandemic? According to penews.com: Luiz Ribeiro, a principal at General Atlantic ${ }^{[10]}$ and a member of Neon's board of directors, explores the company's strengths, the potential impacts of the pandemic, and new opportunities ahead in emerging markets. This includes 3 considerations. 
Consideration 1: Neon provides low-fee banking services to middle-income customers and small business owners in Brazil (Wood, 2019) - both groups believed not be well served by the traditional banking system. Neon's services are even more relevant in the current environment, with the acceleration of digital adoption and customers seeking to reduce fees and expenses. Luiz believed the company had an opportunity to disrupt and transform the traditional banking system and drive financial inclusion.

Consideration 2: Neon is capitalizing on this environment and seeing its value proposition strongly resonate with its customers. The business has fared well during Covid-1, and before the pandemic, Neon generated significant momentum. It is focused on investing in growth and capitalizing on digital acceleration trends, resulting from changing consumer behaviors through the pandemic. General Atlantic

[10]، $\mathrm{s}$ goal is to build a leading, fully digital bank serving the expanded Brazilian middle class and small business.

Consideration 3: Investors expect these changes will shuffle the deck of cards in investment and create important new opportunities for many businesses. The most obvious application of this principle is in the development and application of digital technology, and General Atlantic is seeing behaviors and adoption accelerating. Another consideration when assessing investments in the current climate is the potential for international expansion.

An excellent Fin-Tech Evergreen VC ${ }^{[1]}$ should have deep knowledge of technology and a strong financial analyst team. They focus on the companies and industries, which can provide technical information and use such information to grow and move innovations forward. Included are four areas: consumers, financial service, health care, and high-tech service- They create very unite opportunities for their investors to invest and gain profit. Fin-Tech evergreen fund architecture (Fink, 2014) does not have an end date. When generating funds for an open-ended plan, it is critical to first determine the necessity for obtaining funds and then match this with the demands of investors. Some investors, such as companies and endowments, require long-term capital commitments.

In contrast to the AUM ${ }^{[2]}$ approach, the expenditure of an open-ended fund is negotiated regularly with the stakeholders. It is critical to prepare ahead of time for Fin-Tech evergreen fund investment and fundraising, providing room for follow-ons and opportunistic bets. When realized profits are delivered to investors, a departure will very certainly coincide with another fundraising round.

The portfolio valuation is a crucial element of Fin-Tech evergreen funds; the NAV serves as a performance indicator and accurately assesses the units if significant owners leave or new investors join.

The standard waterfall distribution method is utilized, however, Fin-Tech evergreen funds (Graham, 2018) prefer to return the systematic risk first before the principle. This is a pro-investor strategy that ensures investors are fully compensated for the time value of money.

\section{Theoretical Analysts}

Around 200 FinTech evergreen, VC ${ }^{[1]}$ funds are believed to exist, with roughly 100 of them emerging in the last 20 years (Pitch-book ${ }^{[8]}$ ). To put these arrangements in the context in VC [1,] there are over 10,000 "Venture Capital" funds throughout the world. Since this sort of financing is widespread 
among entrepreneurs, large corporates, and corporate venture divisions, the "real" quantity of evergreens is likely to be more than 200. This money is typically held under an organization's auspices and is not disclosed through regular data methods.

The United States and the United Kingdom account for over three-quarters of the 92 evergreen VC ${ }^{[1]}$ managers that have debuted since 1998. This is unsurprising considering that both countries have the most liquid capital sector and are considered as significant entrepreneurial hotspots inside their respective boundaries.

\section{Evergreen Fund VC by location since 1998}

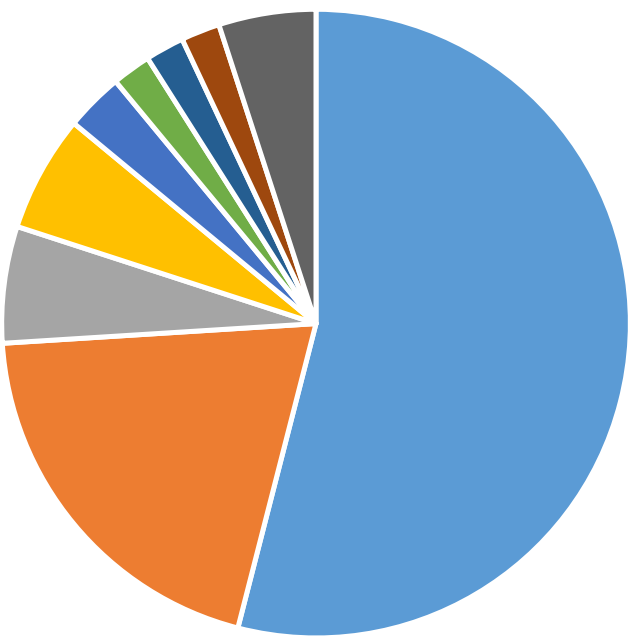

- USA - UK - Canada - Germany - France "Switzerland - Belgium - Inida " others 


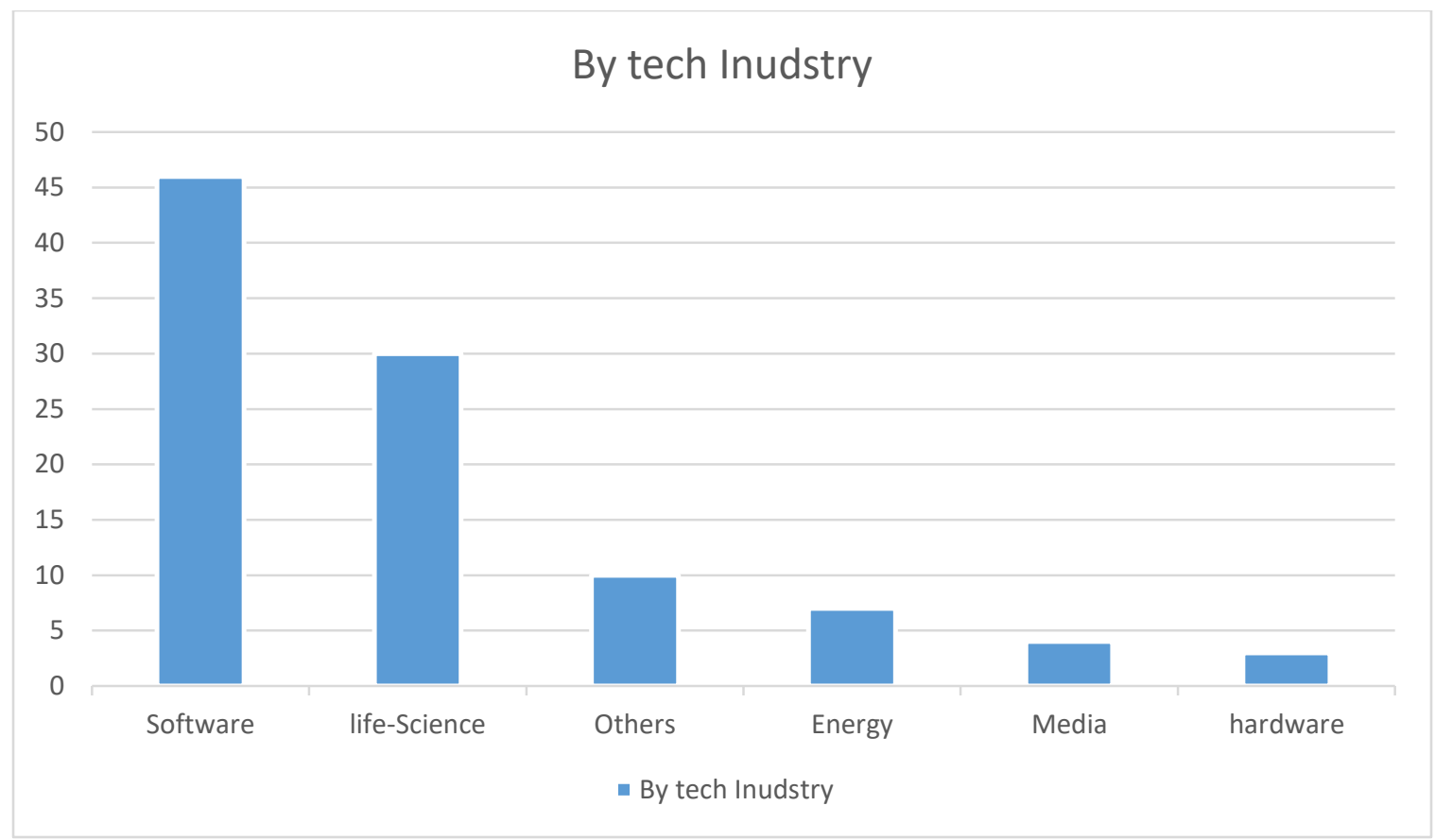

\section{Data proof explanation}

It should come as no surprise that tech firms are by far the most popular investment sector for evergreen VC funds, but what is surprising is the prominence of life sciences. There must be a convincing rationale to raise an evergreen fund other than the fact that it is unique. It is critical to connect it with incentives and to guarantee that it delivers value to investors and the firms in which the team intends to invest.

A Fin-Tech evergreen Fund structure must complement the investing environment or views. Some investment considerations include:

Have a strong conviction in "the sum of the parts" investment and want to use your status as a timing-agnostic investor to nurture this in your portfolio.

Consider the possibility that an investment philosophy may be condensed into a multigenerational business that can exist without you one day.

$\mathrm{LP}^{[3]}$ team with CEO or owners, this strengthens the strategy of long-term growth. Usually, $\mathrm{LP}^{[3]}$ will invest more than $8-10 \%$, but in the general traditional fund, it is usually $1-2 \%$ or even $0 \%$. This special structure avoids the risk of short-term investment but focuses on the long-term commitment of stable projects.

Another example of a Fin-Tech evergreen VC is Sutter Hill Ventures. This firm was founded in 1962, and LP ${ }^{[3]}$ provides highly consistent and long-term assistance to this program. Mike Speiser, managing 
director of Sutter Hill Ventures since 2008, holds 20.3 percent of Snowflake (Levy, 2020) (cloud data outstanding ) shares, including those that will be issued to affiliates. With a total investment of less than $\$ 200$ million, the company has a stake worth around $\$ 12.6$ billion.

Those profits are not yet certain. The stock rose $134 \%$ on Wednesday (09/16/2020) to finish at $\$ 253.93$, but the price might fluctuate dramatically in the next months, based on-trend, the performance of the company, the bigger economy, and the market, while the stock is still tied in for the next few months.

However, long-term supporting $\mathrm{GP}^{[4]}$ is also a very important reason for Fin-Tech evergreen fund to succeed. Only with these long-term partners can the VC team can focus on long-term investment for an industry that lasts at least more than 30 years. Some usual mistakes what kinds of mistakes that VC made are very racial risky but not limited to try to get into IPO ${ }^{[6]}$ in the second or third year. Under the high pressure of investors, fund managers try their best to gain profit and make a risky movement.

Fin-Tech evergreen fund forecasting does need some minor adjustments, however, unlike the percentage of AUM ${ }^{[2]}$ approach, a Fin-Tech evergreen fund will negotiate a strategy/budget with its investors. This is not a major issue because around $70 \%$ of a $\mathrm{VC}$ fund's expenditures are "relatively fixed." The most successful inventions will generate the highest financial rewards. Because fund managers are rewarded based on financial success, Fin-Tech fund managers should keep themselves in a zone where they function and make choices under a 'regular' VC fund. Both GP's ${ }^{[4]}$ and LP's ${ }^{[3]}$ are aware of this, and both intend to maintain it that way.

With Fin-Tech evergreen funds (Graham, 2018) having no end date and the ability to fill them up with new money, investment timelines might appear interminable. Maintaining dry powder for followons and fortuitous bets is critical in any fund, but departures offer another element.

A common misunderstanding about exits in Fin-Tech evergreen funds is that they can recycle money. That is theoretically feasible, thus the name evergreen, although it might be paradoxical in terms of matching the manager's priorities with the LP's ${ }^{[3]}$. There are no prospects of profit if there are no payouts. Because clawback clauses are uncommon in open-ended funds, recycling money might make it difficult to retain excellent investment personnel who are continuously on the lookout for performancebased compensation.

Instead, the financing management must find ways to tie departures to future fundraising, almost as if LPs ${ }^{[3]}$ are in cohorts, bookended by exits. Departures represent a gentle reset in which capital can be refunded and possibly replenished by departed investors. The graphic below depicts an example of the timing of cash flows by activity to help illustrate the cash flows of an evergreen fund. 


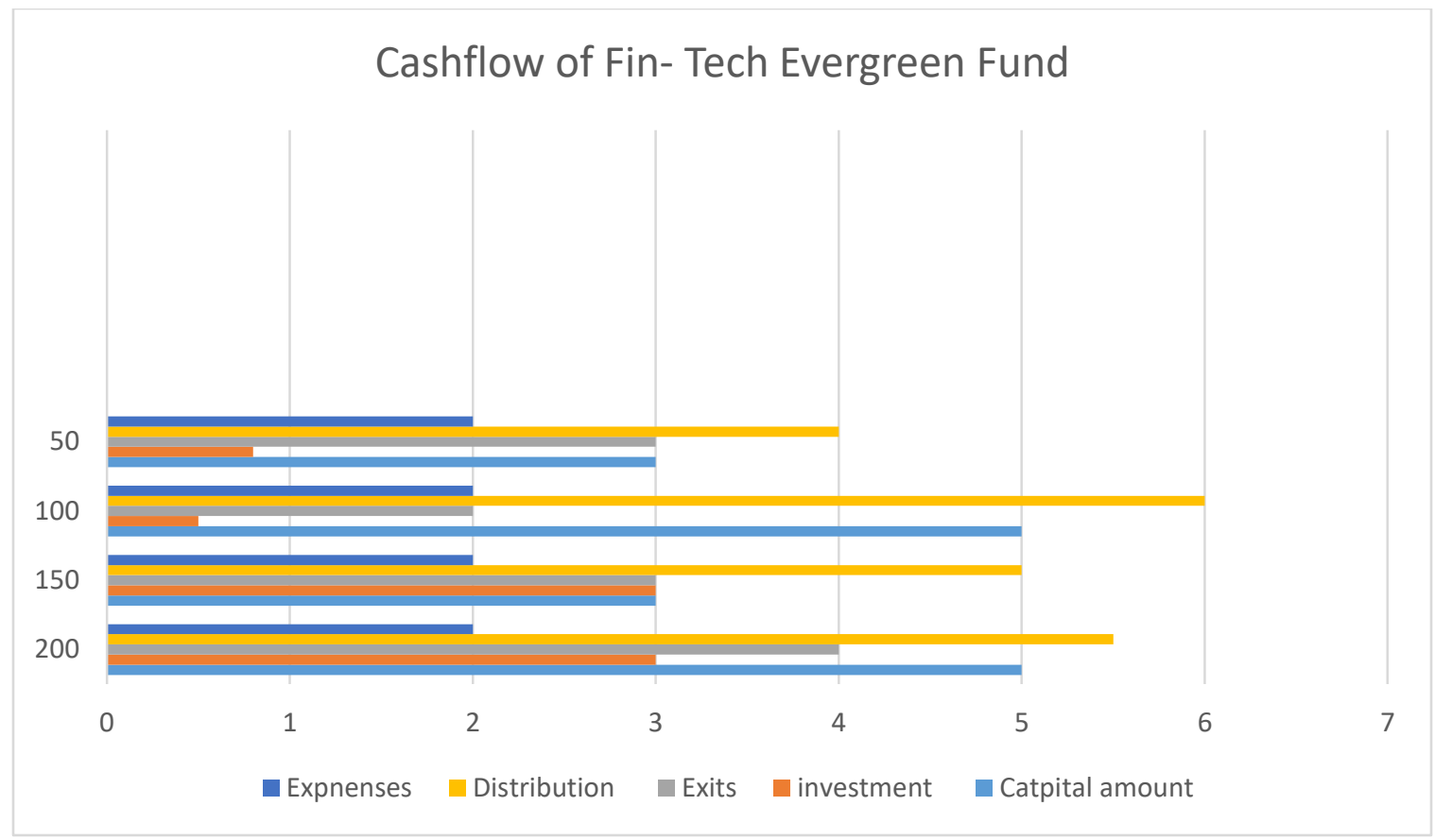

How to manage the cash flow in typical fund waterfalls, the following order exists for distributing returns:

LP's ${ }^{[3]}$ principal

LP's ${ }^{[3]}$ hurdle rates (a minimum IRR ${ }^{[5]}$ return for the fund)

$\mathrm{GP}^{[4]}$ catch-up (a percentage of the $\mathrm{LP}^{[3]}$ hurdle rate)

Final profit share (A split of remaining funds, typically $20 \%$ going to $\mathrm{GP}^{[4]} \mathrm{s}$ )

But how to pick this timely raised and succeed in such unlimited capital gains? When it comes to Fin-Tech evergreen funds, the desired return (or "interest"/"yield") element is generally paid first, followed by the principal. Because an evergreen may theoretically live indefinitely, it is important to adequately compensate investors for the temporal value of their money. If the principal is cleared even before yield, investors may get a lesser return in future years (because of the smaller principal basis) while not yet enjoying substantial profits from the fund. The preferred return is the main determinant of fairness - if the fund cannot outperform the market, it cannot persist. Of course, every fund aspires to outperform the market.

Unlike $P E^{[7]}$ private equity or commercial property funds, capital investment rarely has intermediate cash flows between investment and exit. This can result in distribution circumstances that have nothing for an extended length of time, followed by a massive outflow that can rapidly wash a waterfall down to its final step. Largely accomplished departures are, of course, the reason for celebration; but, the GP ${ }^{[4]}$ must be mindful of their timing since clearing the cap table and profit-taking may necessitate a restructuring of the fund.

In 2010, Warren Buffett gave a speech in his annual investment meeting (Insider Monkey, 2010) and mentioned the bad effect of PE ${ }^{[7]}$ investment value for investors: A VC fund invested in a tech company for 4-5 years, they sold it in the second year, then bought it back in the $3^{\text {rd }}$ year. After all, they sold it 
again in the $5^{\text {th }}$ year. Every time they sold it, they gained 5 times what they originally invested, but they missed a lot of profit in between. They should have had a return of 50 times of their initial investment, but they only made 20 times. They did not gain the maximum profit of the long-term investment.

\section{Discussion}

An intergenerational investing enterprise can expand. Many closed-ended funds are naturally linked to the star GP ${ }^{[4]}$, which brings LPs ${ }^{[3]}$ with them when they depart or the managing business closes down when they retire.

A Fin-Tech evergreen fund can expand and advance its path to a greater level if it has a solid capital structure and a track record of performance. Due to the extreme flexibility afforded by a FinTech evergreen fund structure, there may be a propensity to dabble with bolt-on enterprises like accelerators or company builders.

After all of the research, it is significant there are pros and cons with Fin-Tech evergreen funds in the USA,

Pros include:

Alignment: Managers may concentrate on capital appreciation without being constrained by time limitations. It also works well for entrepreneurs who want to expand their firm sustainably.

Cleaner: Fund investors may adopt a long-term view without having to continually invest.

Flexibility refers to the ability to modify an investing concept and hold various sorts of investments.

Transparency: Instead of accumulating layers of expenses, one budget and a set of management fees are used.

There are downsides, but if open-ended funds were ideal, they would have been more widely used.

Cons include:

Liquidity: For investors in open-ended venture capital funds, the guarantee of liquidity could be a non-starter. Startups do not often pay dividends, and alternative fund marketplaces are limited.

Lumpy cash flows: Massive exits at inconvenient periods can wipe away a waterfall in one swoop.

Valuation: The fund's market capitalization must be clear and accountable.

Startups and co-investors may be unfamiliar with how such funds operate.

China is the second-biggest economy in the world, has a different position and status in the financial industry. The most successful fund that is very close to a Fin-Tech evergreen fund is the GAO WA Fund. But out of the blue, in the beginning, it was a U.S dollar investment fund, which focused on the secondary market. This is one of the very few Fin-Tech evergreen funds in China at this moment it does not limit itself to just invest in the mainstream, secondary market, and buyout, etc., but most of the team look forward to holding a long term investment position in the companies they invested into. For the earlier stage, the middle stage of later stage, even go public or IPO ${ }^{[6]}$, they will still keep holding the stake. 
Besides long-term position, the most important is the funding, long-term investors LP credential is very strict, and $\mathrm{LP}^{[3]} \mathrm{s}$ need to trust $\mathrm{GP}^{[4]}$. They usually choose to invest with Scholar foundation, family foundation, and social security fund, as long-term LP ${ }^{[3]}$. Only with the strong and long term $\mathrm{GP}^{[4]}$, the team will spend the most of their time and energy to design and contribute in long term return modules, and find the company which will last more than 30 years, even do due-diligent of the background and culture the company to estimate their ability to succeed.

The other Fin-Tech evergreen fund is "Capital Today". In 2014, this fund published a 4 billion dollar fund, investment term is 28 years, allowing "Capital Today" invested in the long term and Xin Xing China stock, the LP ${ }^{[3]}$ is U.S. Endowment Fund and Family Capital, from Tokyo Japan. In 2015, the famous Alibaba (Block, 2019) Group established a nonprofit fund ${ }^{[8]}$ : Alibaba foundation, to support entrepreneurs from Taiwan and Hong Kong, continuing to invest in many qualified companies to achieve stable gain from long term capital investment.

\section{Conclusion}

Compare to the old capitalize financial world, how China: the second biggest economy in the world, should invest in the evergreen fund? Below are some starting points:

The pros include:

Alignment: GP ${ }^{[4]}$ can concentrate on capital appreciation without regard for temporal constraints. It also works well for entrepreneurs who want to expand their firm sustainably, as they can spend more time on actual improvements rather than racing to obtain cash to report in the annual meeting.

Cleaner: $\mathrm{LP}^{[3]}$ can take a long-term view without constantly needing to invest.

Compare to short-term investment goals, Fin-Tech evergreen fund can multiple the original investment by more than 20 times and save a lot of middle transaction fees and huge research fees by re-investing in and out on different portfolios.

The cons include:

Illiquidity: For LP ${ }^{[3]}$ investors in China's evergreen VC funds, the assurance of liquidity may be rendered irrelevant. Startups do not often pay dividends, and secondary fund markets are limited.

Huge withdrawals at unforeseen periods may empty a waterfall in one go, much like any other evergreen fund in the United States, thus cash flow is limited.

Valuation: The net asset value of the fund must be transparent and consistent, such a requirement in the recent China environment, when some regulation has not existed, it is difficult for the law enforcement agency to process and protect investors.

Perception: Unlike-40 years old General Atlantic ${ }^{[9]}$ or Silicon Valley Shutter Hills Ventures, there are not too many long-term achievement $\mathrm{GP}^{[4]}$ in china who can post their past successful history of investing in the evergreen fund. This is just the truth which evergreen fund is still very hard to promote in China.

Immature Regulatory system and Tax environment. For example, Fin-tech evergreen fund will distribute stock directly to $\mathrm{LP}^{[3]} \mathrm{LP}^{[3]}$ will not pay taxes in the USA, and this is a preferable arrangement. But in China, this is not the same. Everyone has to pay taxes. When LP ${ }^{[3]}$ becomes a silent shareholder, it means he left the fund. Sometimes the fund is not registered with a cash fund, but the amount of 
distribution, the other stock option or company ownership, or even partial real estate ownership to invest into the fund.

Interestingly, long term Fin-Tech evergreen fund is like running a marathon in the tech business. If everyone wants to make easy money, such a way of investment will not be the choice. Investment is also based on the GP ${ }^{[4]}$ 's and LP ${ }^{[3]}$ 's philosophy that will be more and more Fin-tech evergreen fund blooming to catch the wave of blockchain and Artificial intelligence wave of the new industrial revolution.

We will expect shortly, China, the fastest developing country in the east, soon should develop more evergreen funds for their domestic or foreign investors to enjoy the profit of the technology innovation of the 21-century industry revolution.

\section{Annotation}

1, VC - Venture capital (VC) is a type of private equity ${ }^{[7]}$ funding offered by venture capital organizations or funds to startups, early-stage, and developing companies with significant growth potential or that have proven strong growth. Venture capital businesses or funds make investments in these early-stage enterprises in exchange for stock or a share in the company. Venture capitalists bear the risk of funding hazardous start-ups with the expectation that most of the companies they sponsor will succeed. Because companies confront a high level of uncertainty, VC investments have a high mortality rate. Start-ups are often built on a new technology or business strategy and come from high-tech industries such as information technology (IT), clean technology, or biotechnology.

2 AUM- Assets Under Management (AUM) is the total value of all investments handled by a fund or group of funds, a venture capital firm, a brokerage business, or a person licensed as an investment adviser or portfolio manager.

3, LP - When two or more people enter into a company jointly, one or more of the partners is only responsible up to the amount of their investment. The LP's general partner ${ }^{[3]}$ has limitless responsibility.

4, GP- The creators of a venture capital firm are known as General Partners (GPs), while the investors they seek are known as Limited Partners (LPs). High-net-worth people, large corporates, institutions, large businesses, endowment funds, pension funds, and funds of funds are all examples of limited partners.

5, IRR- Internal rate of return is a term that refers to the rate of return on an investment. It displays the yearly percentage return received by an investor's portfolio firm or fund (or expects to earn). The return on a fund's portfolio is measured by the deal IRR, often known as gross IRR. 
6, IPO- The process of selling shares of a private business to the public in a fresh stock issuance is known as an initial public offering (IPO). A corporation can raise cash from the general public by issuing public shares.

7, PE- Private equity is a form of equity and one of the asset classes that include equity and debt instruments in operational firms that are not publicly listed on a stock market. However, the word has evolved to refer to the process of bringing a firm into private ownership to reorganize it before reselling it at a profit.

8, Pitch-Book is a sales document prepared by an investment bank or business that outlines the firm's major characteristics and is used by the firm's sales team to help sell products/services and attract new clients. Pitch books assist salespeople to recall significant benefits and give visual aids while giving presentations to clients.

\section{Reference:}

AltAssets. (2018, July 16). General Atlantic taps evergreen fund to sink Om in Greensill | AltAssets Private Equity News. https://www.altassets.net/private-equity-news/by-news-type/dealnews/general-atlantic-taps-evergreen-fund-to-sink-250m-in-greensill.html

Block, F. (2019, May 17). Alibaba Details Its Social Impact as Jack Ma Prioritizes Philanthropy| Barron's. https://www.barrons.com/articles/alibaba-details-its-social-impact-as-jack-ma-prioritizesphilanthropy-01558126117

Fink, B. (2014, February 25). What is an Evergreen Fund Structure? https://www.axial.net/forum/evergreen-fund-structure/

Graham, A. (2018). Exploring Evergreen Funds with a VC Investor Who Raised One. https://www.toptal.com/finance/venture-capital-consultants/evergreen-funds

Insider Monkey. (2010, December 1). Here's What Warren Buffet Thinks About the Efficient Market Hypothesis. https://www.businessinsider.com/warren-buffett-on-efficient-market-hypothesis-201012

Levy, A. (2020, September 16). Snowflake investor Sutter Hill controls \$12.6 billion after IPO pop. https://www.cnbc.com/2020/09/16/snowflake-investor-sutter-hill-holds-11point6-billion-after-ipopop.html

Wood, S. (2019, November 27). Latin America roundup: Neobanks raise \$205M+; Softbank backs VTEX | TechCrunch. https://techcrunch.com/2019/11/27/latin-america-roundup-neobanks-raise-205msoftbank-backs-vtex/ 